Sternberg et al. ${ }^{9}$ that traces of carbon tetrachloride in carbon monoxide flames give rise to ions with an efficiency similar to methane appears to eliminate the suggestion that hydrogen participates in any form. However, this result must be regarded as inconclusive because apparently no precautions were taken to exclude all traces of moisture from the gases used.

I should like to acknowledge an I.C.I. Fellowship. E. M. BULEWICZ

Department of Physical Chemistry,

University of Cambridge.

${ }^{1}$ McWilliam, I. G., J. Chromatog., 6, 110 (1961).

${ }^{2}$ Dewar, R. A., J. Chromatog., 6, 312 (1961).

${ }^{3}$ Ettre, I. S., J. Chromatog., 8, 525 (1962).

${ }^{4}$ Perkins, G., jun., Rouayheb, G. M., Lively, L. D., and Hamilton, W. C., Gas Chromatography, Third Intern. Symp., 1961 (Academic Press Ine., New York, 1962).

${ }^{5}$ Bulewicz, E. M., and Padley, P. J., Ninth Intern. Symp. Combustion, 1962 (Academic Press Inc., New York, 1963).

"Green, J. A., and Sugden, T. M., Ninth Intern. Symp. Combustion, 1962 (Academic Press Inc., New York, 1963).

' Calcote, H. F., Twenty-sixth AGARD Propulsion and Energetics Panel Meeting (Pisa, 1965).

${ }^{8}$ Calcote, H. F., Combustion and Flame, 1, 385 (1957).

- Sternberg, J. C., Gallaway, W. S., and Jones, D. T. L., Gas Chromatography Third Intern. Symp., 1961 (Academic Press Inc., New York, 1962).

${ }^{10}$ Lewis, B., and von Flbe, G., Combustion, Flames and Explosions of Gases, .

"Handbook of Physics and Chemistry, forty-third ed. (Chemical Rubber Co. Inc., Cleveland, Ohio, 1961).

\section{Separation of Coumarins}

SoRptron on cation exchange resins allows the complete separation of some coumarins ${ }^{1}$ in dilute solution using a simple technique. A column of the styrene-divinylbenzene copolymer-type sulphonic acid cation exchange resin, Dowex $50 W-X 4(-100,+200$ mesh, Dow Chemical Co.), in the hydrogen form (bed length, $53 \mathrm{~cm}$; bed volume, 131 c.c.) has been used for this purpose.

The coumarins investigated are divided into two groups. Group $A$ includes coumarin, 7-hydroxycoumarin, 8hydroxycoumarin and 7,8-dihydroxy-4-methyl coumarin; Group $B$ includes 7-methylcoumarin, 3,4-dimethylcoumarin, 7-methoxyeoumarin, 6-methoxy-4-methylcoumarin and 6,7-dimethoxy-4-methylcoumarin.

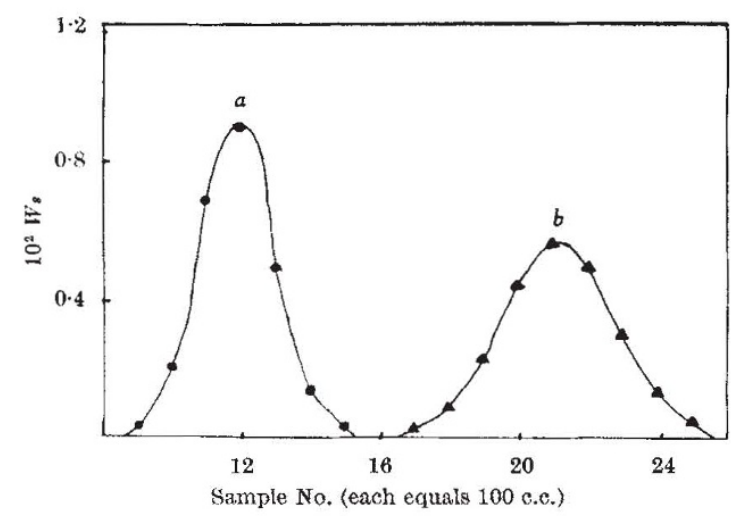

Fig. 1. Separation of (a) 7 -hydroxycoumarin $\left(W=2.508 \times 10^{-2}\right)$ and (b) 7-methoxycoumarin $\left(W=2.446 \times 10^{-2}\right)$. W, solute content in mequiv./100 c.c. of solution and sorbed on the resin bed. $W_{*}$, No, of m.equiv, of solute in 100 c.c. of effluent sample.

100 c.c. of solution $\left(\sim 5-6 \times 10^{-4} \mathrm{M}\right)$ in 10 per cent methanol (by volume), containing only one compound from each group, was passed through the column at the rate of 5 c.c./min and the run was then continued with 10 per cent methanol (by volume) as influent, to elute the sorbed solutes on the column. The effluent was collected in samples and estimated for solute content by ultraviolet absorption ${ }^{2}$. Each compound was eluted separately.
Fig. 1 shows the separation obtained with a mixture of 7-hydroxycoumarin and 7-methoxycoumarin.

D. J. Patel

S. L. BAFNA

Department of Chemistry,

Faculty of Science,

M.S. University of Baroda,

Baroda, India.

${ }^{1}$ Shah, R. S., and Bafna, S. L., Nature, 208, 76 (1965).

${ }^{2}$ Shah, R. S., and Bafna, S. L., Ind. J. Chem., 1, 400 (1963).

\section{Chloro-olefine Complexes of Platinum}

ALthoUGH the reactions of fluoro-olefines with transition metal complexes have yielded very stable fluoro-olefine and fluorocarbon complexes ${ }^{1-3}$ analogous reactions with chloro-olefines have hitherto resulted in chlorination to form metal chlorine bonds ${ }^{4-6}$. We find, however, that on refluxing a benzene solution of $\mathrm{Pt}\left(\mathrm{PPh}_{3}\right)_{4}$ (ref. 7) with tetrachloroethylene the complex $\left(\mathrm{Ph}_{3} \mathrm{P}\right)_{2} \mathrm{PtC}_{2} \mathrm{Cl}_{4}$ is formed in high yield as white air stable crystals with a melting point of $278^{\circ} \mathrm{C}$ dec. This would seem to be the first example of a perchloro-olefine transition metal complex. The reaction of $\mathrm{Pt}\left(\mathrm{PPh}_{3}\right)_{4}$ with a number of halogenoolefines, for example, tetrafluoroethylene, trichloroethylene, trans-dichloroethylene, 1,1,1-trifluoro-2,3,3-trichloro2 -propene, appears to be a general reaction for the preparation of complexes of the type $\left(\mathrm{Ph}_{3} \mathrm{P}\right)_{2} \mathrm{Pt}$ olefine. The complexes prepared in this work and the recently described tetracyanoethylene ${ }^{8}$ complex are considerably more stable than the olefine complexes of this type which were originally prepared with trans-stilbene, trans 4,4, dinitrostilbene and acenaphthylene ${ }^{\theta}$.

The infra-red spectrum of the tetrachloroethylene complex shows bands owing to carbon chlorine vibrations at 910,804 and $796 \mathrm{~cm}^{-1}$. The other chloro-olefine complexes also show carbon chlorine bands in this region of the infra-red. No band that can be attributed to a $\mathrm{C}=\mathrm{C}$ stretching frequency ${ }^{10}$ is observed in the infra-red spectra of the tetrachloroethylene and trichloroethylene complexes between 2,000 and $1,500 \mathrm{~cm}^{-1}$. The compounds are probably best regarded as complexes of $\mathrm{Pt}$ (II), the olefine forming a three membered ring with the platinum by way of two $\alpha$ bonds.

W. J. BIAAND

R. D. W. Kғ.мmitт

Department of Chemistry,

University of Leicester.

${ }^{2}$ Mays, M. J., and Wilkinson, G., J. Chem. Soc., 6629 (1965).

${ }^{2}$ Parshall, G. W., and Jones, F. N., J. Amer. Chem. Soc., 87, 5356 (1965).

"Treichel, P. M., and Stone, P. G. A., Adv. Organometal Chem., 1, 143 (1964).

'Hoehn, H. H., Pratt, L., Watterson, K. F., and Wilkinson, G., J. Chem. Soc., 2738 (1961).

Wilford, J. B., Forster, A., and Stone, F. G. A., J. Chem. Soc., 6519 (1965). "Clark, H. C., and Tsang, W. S., Chem. Commun., 123 (1966).

"Malatesta, L., and Ugo, R., J. Chem. Soc., 2080 (1963).

"Baddley, W. H., and Venanzi, L. M., Inorg. Chem., 33 (1966).

"Chatt, J., Shaw, B. L., and Williams, A. A., J. Chem. Soc., 3269 (1962).

${ }^{10}$ Chatt, J., and Duncanson, L. A., J. Chem. Soc., 2939 (1953),

\section{Doubly charged Negative Ions of Oxygen, Fluorine, Chlorine and Bromine}

ELECTRON impact processes give rise to both positive and negative ions. The negative ions are, in general, only about $10^{-3}$ times as intense as the positive ions. In contrast with positive ions, only singly charged negative ions have previously been reported. Calculations involving the crystalline state, where doubly charged negative ions (such as $\mathrm{O}=$ and $\mathrm{S}=$ ) apparently do exist, indicate that the formation of $\mathrm{O}=$ from $\mathrm{O}^{-}$requires $7 \cdot 8 \mathrm{eV}$ in the gas phase ${ }^{1}$. The lifetime of a doubly charged ion in the gas phase would be expected to be short and has been predicted to be $10^{-10} \mathrm{sec}$ or less ${ }^{2}-$ too short for observation 